\title{
Fe Alloys: Production and Metallurgical Aspects: Part II
}

\author{
DEAN GREGUREK, ${ }^{1,5}$ ZHIWEI PENG, ${ }^{2,6}$ CHRISTINE WENZL, ${ }^{3,7}$ \\ and JESSE F. WHITE ${ }^{4,8}$ \\ 1.-Technology Center Leoben, RHI AG, Magnesitstrasse 2, 8700 Leoben, Austria. 2.-School of \\ Minerals Processing and Bioengineering, Central South University, Changsha 410083, Hunan, \\ China. 3.-RHI AG, Wienerbergstrasse 9, 1100 Vienna, Austria. 4.-Elkem Carbon AS, 4675 \\ Kristiansand, Norway. 5.-e-mail: dean.gregurek@rhi-ag.com.6.-e-mail: zwpeng@csu.edu.cn. \\ 7.—e-mail: christine.wenzl@rhi-ag.com. 8.—e-mail: jesse.white@elkem.no
}

The present JOM topic is the sequel to the Ferroalloys topic of December 2016. Due to the large number of high-quality articles submitted, we decided to follow the example of many successful movies and novels, namely_providing you with Part II. In this issue, you will find interesting updates from the world of ferroalloy production, ranging from furnace technology to production processes. In addition, contributions concerning Minor Elements can be found in the Technical Communications section of this issue.

The history of metallurgy dates back to medieval and even ancient times. We have come a long way since the belief that everything consists of the four elements, Earth, Water, Wind and Fire, but today's metallurgists and furnace operators still have to deal with unexplained effects and are continuously striving for furnace and process improvements. Every metal producer and every operator has its own special philosophy and recipe to reach the desired outcome, partly based on knowledge, partly on (unexplainable) "magic". For the alchemists and sorcerers in medieval times (and numerous novels, movies and computer games), it was all about choosing the right cauldron, magic ingredients, and right magic spell. Today, it is all about choosing the suitable furnace and slag and knowing how to operate the process.

Generally, the standard ferroalloy production processes are well established and have been used for many decades and even centuries. However, there is still room for optimization, e.g., regarding energy consumption and further adjustments that are sought for because of changing conditions, e.g., increasing production and supply of fine ores.

Dean Gregurek, Zhiwei Peng, and Jesse White are the JOM advisors for the Pyrometallurgy Committee of the TMS Structural Materials Division, and guest editors for the topic Fe Alloys: Production and Metallurgical Aspects: Part II in this issue.
The first article in this topic, "ESS Smelting Technology" by Lourens Jacobus Erasmus and Louis J. Fourie, describes a novel furnace technology that combines fossil fuel pre-heating and solid state reduction in a single furnace to enable production of molten metal and slag, with only a minimum amount of electrical energy through optimization of thermal energy consumption. This technology is applicable to direct smelting of fine ores without or with minimal input material preparation. The ESS technology provides a competitive opportunity to minimize electrical energy consumption during smelting processes using various ores. A pilot ESS furnace is being constructed at Mintek to validate the process as well as the equipment design parameters for full development of this technology for selected applications.

In the next article, entitled, "Considerations for scale-up of ferronickel electric smelting furnaces," Rodney Hundermark and Lloyd Nelson propose common trends and some new metrics for the scale-up of nickel laterite smelting operations for FeNi production. The optimal process needs a fine balance between the metallurgical requirements of the process (i.e., feed composition, nickel recovery, energy consumption and product quality) and the capabilities of the feeding, tapping and off-gas systems, and especially of the furnace crucible and electrical system. The scale-up of nickel laterite smelting operations over the last 50 years has witnessed a tenfold increase in furnace power input. The present study incorporates the combination of electrode power densities and the impact of alloy nickel grade on gas generation rates, and hence local electrode gas fluxes, which may have an impact on the future scale-up of FeNi furnaces.

Direct current (DC) arc furnace smelting is still regarded as a new technology, even though it is not that new any more. However, many companies still 
refrain from using DC furnaces and stick to the well-established AC furnaces because DC furnaces are still often seen as a "hard-to-control black-box".

To change this mindset, the next article, "The Exact Art and Subtle Science of DC Smelting: Practical Perspectives on the Hot Zone" by Isabella J. Geldenhuys, provides a summary of good practices or principles for DC smelting as experienced by Mintek, South Africa. The article provides a practical guideline for furnace builders and operators. Topics like thermal efficiency, arc length management, mass balances, metallurgical control and many others are covered and discussed in the article. The successful open-arc smelting and the proper control start with managing the balance between power and feed.

Also, in the next article, "Computational Modelling of Arc-Slag Interaction in DC Furnaces," Quinn Gareth Reynolds sheds more light on the black-box of DC furnaces. The authors study the arc's interaction with the molten bath inside the furnace using a multiphase, multi-physics computational magnetohydrodynamic model implemented in the OpenFOAM ${ }^{\circledR}$ framework. The results from the computational solver were compared to empirical correlations to quantify the arc-slag interaction effects. Coupling of a magnetohydrodynamic plasma arc solver to an existing multiphase fluid flow solver was successfully achieved, resulting in a computational model able to capture some of the complex physical behavior and dynamics of the arc-bath interaction zone inside DC arc furnaces. There was reasonable agreement between the present model and theoretical relationships from turbulent jet theory for the dimensions of the cavity formed by the arc in the molten slag layer. The comparison of the model results with semi-empirical correlations used to calculate the electrical parameters of DC furnaces showed lower values of the predicted voltages in the computational model despite the correct trends captured.

In the next article, entitled "Pilot Scale Production of Manganese Ferroalloys Using Heat Treated Mn-Nodules," Merete Tangstad et al. describe a novel and unique raw material for FeMn production that enables certain advantages during processing. They report on the results of a pilot-scale experiment done with Mn-nodules, Comilog ore and limestone. The main observation from the pilot experiment was that $\mathrm{Mn}$-nodules follow the reduction trend previously seen in pilot- and industrial- scale furnaces for other ores. The furnace interior after the experiment with Mn-nodules is similar to that after HC FeMn experiments with other Mn sources, such as Comilog ore. During the experiments, it was found that the $\mathrm{MnO}$ reduction occurs mainly on the top of the cokebed (high-temperature area) where $\mathrm{Mn}$ nodules melt into a liquid phase and a solid $\mathrm{MnO}$ phase. The slag was tapped close to the liquidus composition, which is linearly dependent on the basicity, described as $[\mathrm{B}=(\mathrm{CaO}+$ $\left.\mathrm{MgO}) /\left(\mathrm{SiO}_{2}+\mathrm{Al}_{2} \mathrm{O}_{3}\right)\right]$.

The last article in this topic, "Airborne Emissions from Si/FeSi Production" by Ida Teresia Kero et al., provides a comprehensive literature review on current knowledge developed in, and relevant to, the $\mathrm{Si}$ and FeSi production industry. The article is primarily based on information available in the open literature but also in some previously unpublished reports of utmost relevance to the topics. It contains state-of the-art overviews for gaseous and particle-bound airborne emissions. Relevant technological aspects for the control and reduction of greenhouse gases, nitrogen oxides, polyaromatic hydrocarbons, heavy metals and particulate matter are introduced in the article.

The following papers being published under the topic of Fe Alloys: Production and Metallurgical Aspects: Part II provide excellent details and research on the subject. To download any of the papers, follow the url: http://link.springer.com/jour nal/11837/69/2/page/ 1 to the table of contents page for the February 2017 issue (vol. 69, no. 2).

- "ESS Smelting Technology" by L.J. Erasmus and L.J. Fourie.

- "Considerations for Scale-Up of Ferronickel Electric Smelting Furnaces" by R.J. Hundermark and L.R. Nelson.

- "The Exact Art and Subtle Science of DC Smelting: Practical Perspectives on the Hot Zone" by I.J. Geldenhuys.

- "Computational Modelling of Arc-Slag Interaction in DC Furnaces" by Quinn G. Reynolds.

- "Pilot Scale Production of Manganese Ferroalloys Using Heat Treated Mn-Nodules" by Merete Tangstad, Eli Ringdalen, Edmundo Manilla, and Daniel Davila.

- "Airborne Emissions from Si/FeSi Production" by Ida Kero, Svend Grådahl, and Gabriella Tranell. 